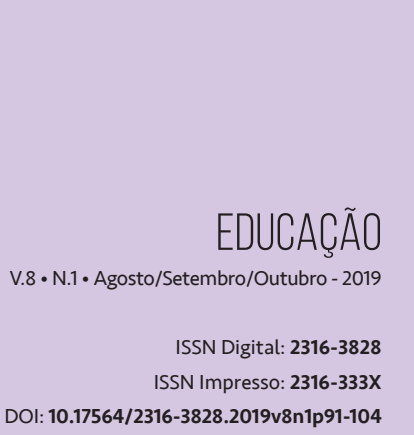

\section{PERCEPÇÕES ATRIBUÍDAS AO ESTÁGIO DE DOCÊNCIA NO ENSINO SUPERIOR}

Júlia Graciela de Souza ${ }^{1}$

Mariana Lopes Junqueira ${ }^{2}$ Marcia Regina Selpa Heinzle ${ }^{3}$

\section{RESUMO}

O Estágio de Docência (ED) no Ensino Superior (ES) configura-se como um processo de formação docente em Programas de Pós-Graduação. Esta pesquisa tem por objetivo analisar percepções dos mestrandos atribuídas ao ED no ES a partir de relatórios de ED de um Curso de Mestrado em Educação de uma Universidade de Santa Catarina (SC). Trata-se de uma pesquisa qualitativa e de Análise Documental (CELLARD, 2012) em que foram analisados 15 relatórios de estagiários docentes produzidos nos anos de 2015 e 2016. Os relatos apontam percepções positivas sobre a experiência de docência no ED, destacando: aprendizado da prática docente no ES; valorização do docente orientador de estágio; papel da docência e lições adquiridas no estágio de docência. Os relatos não assinalam percepções negativas ou críticas, entretanto, aspectos identificados na análise documental preliminar permitem questionar as informações. Dessa forma, os componentes da estrutura do relatório devem ser revistos, bem como a necessidade de novos estudos para identificar possíveis dificuldades e elucidar proposições para qualificar o ED e a formação docente para o ES.

\section{PALAVRAS-CHAVE}

Formação Docente. Ensino Superior. Estágio de Docência. Relatório de Estágio. Análise Documental. 


\section{ABSTRACT}

The Teaching Internship (TI) in Higher Education (HE) is configured as a process of teacher training in postgraduate programs. This research aims to analyze perceptions regarding $\mathrm{TI}$ attributed by the masters of a post-graduation program stricto sensu in Education of a Santa Catarina University. This is a qualitative research and Documentary Analysis (CELLARD, 2012) in which 15 reports of the trainees produced in the years 2015 and 2016 were analyzed. The reports indicate positive perceptions about the experience of teaching in the $\mathrm{HE}$, in which the following stand out: learning of teaching practice in $\mathrm{HE}$; appreciation of the teacher advisor; role of teaching and lessons learned in the teaching stage. The reports do not indicate negative or critical perceptions, however, aspects identified in the preliminary documentary analysis allow questioning the information. Thus, the components of the report structure should be reviewed, as well as the need for further studies to identify possible difficulties and elucidate propositions to qualify $\mathrm{TI}$ and teacher education for $\mathrm{HE}$.

\section{KEYWORDS}

Teacher Training. Higher education. Teaching Internship. Internship report. Documentary Analysis.

\section{RESUMEN}

La Práctica/Etapa Docente (ED) en la Enseñanza Superior (ES) se configura como un proceso de formación docente en Programas de Posgrado. Esta investigación tiene por objetivo analizar las percepciones de los maestros vinculadas al ED en el ES, a partir de informes de ED de un Curso de Maestría en Educación de una Universidad de Santa Catarina (SC). Se trata de una investigación cualitativa y de Análisis Documental (CELLARD, 2012) en el que se analizaron 15 informes de pasantes docentes producidos en los años 2015 y 2016. Los relatos apuntan percepciones positivas sobre la experiencia docente en el ED, en el que destacan: aprendizaje de la práctica docente en el ES; valorización del docente orientador de prácticas; el papel de la docencia y las lecciones adquiridas en la etapa de docencia. Los relatos no señalan percepciones negativas o críticas, sin embargo, aspectos identificados en el análisis documental preliminar permiten cuestionar las informaciones. De esta forma, los componentes de la estructura del informe deben ser revisados, así como la necesidad de nuevos estudios para identificar posibles dificultades y elucidar proposiciones para calificar el ED y la formación docente para el ES.

\section{PALABRAS CLAVE}

Formación docente. Enseñanza superior. Práctica Docente. Relato de prácticas. Análisis Documental. 


\section{INTRODUÇ̃̃̃O}

Uma das possibilidades de formação docente para atuação no Ensino Superior (ES) no Brasil acontece na Pós-Graduação, da qual podemos destacar como uma importante iniciativa para o processo o Estágio de Docência (ED). De acordo com o artigo $66^{\circ}$ da Lei $n^{\circ} 9.394$, que estabelece as Diretrizes e Bases da Educação Nacional, “a preparação para o exercício do magistério superior far-se-á em nível de pós-graduação, prioritariamente em programas de mestrado e doutorado” (BRASIL, 1996, p.5). Diante dessa consideração, Veiga (2006, grifos nossos) destaca que a referida lei utiliza a palavra preparação ao invés de formação, termos que conceitualmente diferem. Conforme Joaquim, Vilas Boas e Carrieri (2013, p. 355):

O processo de formação vai além da preparação, uma vez que está intimamente relacionado à aquisição de conhecimentos e ao desenvolvimento de habilidades e envolve um aprimoramento didático, o que, em um processo preparatório, nem sempre é oportunizado. Já quando se fala em preparo, subentende-se que a pessoa detém aquele conhecimento e, portanto, está preparada.

Assim, temos o olhar voltado à formação do docente do ES, considerando que, segundo Cunha (2012), a maioria dos egressos dos Programas de Pós-Graduação (PPG) stricto sensu, no Brasil, almejam lecionar no ES. Ainda que conhecendo esse fato, são poucos os PPG que ofertam disciplinas pedagógicas com foco na docência no ES ou nas metodologias do ES, reforçando a ideia de que, para ser docente no ES, basta ter o domínio do conhecimento específico, sendo desnecessária a formação pedagógica (CUNHA, 2012; PIMENTA; ANASTASIOU, 2014).

Zanchet, Cunha e Souza (2009) apontam que há uma concepção de que, quanto maior o conhecimento específico o docente do ES possuir, melhor será o seu desempenho profissional docente. Faz-se necessário que os docentes questionem sobre suas necessidades ante o ensino do conhecimento específico. As autoras refletem que o modelo de formação para a docência no ES é fundamentado na pesquisa, pois é com base nela que se define o parâmetro de qualidade dos PPG stricto sensu, ocasionando a valorização dos saberes dessa prática e do campo de conhecimento específico.

Ao criticarem essa acepção, Soares e Cunha (2010) e Cunha (2012) afirmam que os PPG focam suas atividades na formação para a pesquisa acadêmica e não na formação pedagógica, apesar de serem atividades distintas que, segundo as autoras, podem ser articuladas e contribuir para a formação de docentes autônomos e críticos. Assim, a articulação dessas duas atividades traria uma maior qualidade para o processo de formação docente.

Diante do exposto, consideramos que, além das disciplinas pedagógicas nos PPG, o ED também é uma iniciativa importante para qualificar a formação do futuro docente do ES. O ED foi instituído pela Coordenação de Aperfeiçoamento de Pessoal de Nível Superior (CAPES), com o objetivo de preparar os pós-graduandos e qualificar o ensino de graduação no Brasil. Problematizamos novamente a utilização do termo "preparo" ao invés de "formação" no documento da CAPES, como citado anteriormen- 
te, esse termo produz a ideia de que, com o conhecimento, a pessoa está preparada para a docência (JOAQUIM; VILAS BOAS; CARRIERI, 2013).

A portaria $n^{\circ} 76$ que Regulamenta o Programa de Demanda Social da CAPES, traz em seu artigo $18^{\circ}$, a obrigatoriedade do ED para todos os bolsistas, compreendendo o estágio como "parte integrante da formação do pós-graduando" (CAPES, 2010). Essa portaria traz alguns critérios para o ED, mas, conforme Cunha (2012), não menciona orientação aos Programas de como deve ocorrer o estágio, assim como não instituiu nenhuma forma de acompanhamento do mesmo. Segundo Lima e Braga (2016), a obrigatoriedade do ED se deve ao fato de os cursos de Pós-Graduação stricto sensu serem "uma porta de entrada para a docência universitária, já que o estágio é uma das escassas atividades nos cursos voltadas para a formação docente” (LIMA; BRAGA, 2016, p. 76).

Um estudo realizado por Soares e Cunha (2010) sobre a formação docente para o ES em dois Programas stricto sensu aponta que a formação de docentes é uma questão secundária, inclusive em PPG em Educação, nos quais a realização de ED acontece para cumprir a determinação da CAPES, ao invés de ser considerado como um instrumento eficaz para a formação do futuro docente do ES. Infelizmente, isso se deve à reprodução de uma lógica nacional de formar pesquisadores, em que os programas stricto sensu,

[...] tendem a concentrar suas ações a fim de atender as exigências dos processos avaliativos da CAPES, esvaziando as energias que poderiam ser investidas em iniciativas e construções sintonizadas com o contexto político, social, cultural no qual estão inseridos. (SOARES; CUNHA, 2010, p.124-125).

Sobre isso, Pachane (2006) aponta que as Universidades devem instituir propostas de formação pedagógica na Pós-Graduação que integrem as demais atividades desenvolvidas, não se restringindo apenas à pesquisa, promovendo, assim, a reflexão sobre a prática docente no ES.

O presente estudo, considerando essa discussão, está inserido na temática formação docente para o ES e apresenta uma pesquisa realizada em um Curso de Mestrado de um PPG em Educação. O objetivo é analisar percepções dos mestrandos atribuídas ao ED no ES, a partir de relatórios de ED de um Curso de Mestrado em Educação de uma Universidade de Santa Catarina (SC).

O ED foi implantado no referido Programa em 2002 e, atualmente, segue a Resolução Interna no 047 (UNIVERSIDADE, 2012) que regulamenta o ED de todos os PPG stricto sensu (mestrado e doutorado) oferecidos pela Universidade. Segundo o artigo $3^{\circ}$, o Estágio tem por objetivo geral “I - capacitar para a docência no ensino superior os alunos matriculados em cursos de pós-graduação stricto sensu" (UNIVERSIDADE, 2012, p. 1). A duração do ED para os estudantes de mestrado é de um semestre, em acordo com a Portaria $n^{0} 76$ (CAPES, 2010).

A Universidade optou por instituir a obrigatoriedade da realização do estágio e do relatório de estágio para todos os mestrandos que recebem bolsa provenientes da CAPES, da Fundação de Amparo à Pesquisa e Inovação do Estado de Santa Catarina (FAPESC) e de gratuidade da própria Universidade. Aos demais mestrandos, a realização do estágio é optativa, assim como a produção do relatório. 0 mestrando, contudo, recebe um documento comprovando a realização do estágio mediante a entrega do relatório. 
Nas próximas seções, abordaremos o método utilizado na pesquisa realizada a partir dos relatórios de ED de um PPG em Educação de uma Universidade de SC. Posteriormente, apresentamos a análise preliminar dos relatórios de ED, análise das percepções dos mestrandos atribuídas ao ED no ES e, na última seção, traçamos algumas considerações.

\section{MÉTODO}

A pesquisa é de cunho qualitativo e de Análise Documental (CELLARD, 2012). Possui como corpus relatórios de ED do Mestrado em Educação do PPG stricto sensu de uma Universidade de SC. Por meio de solicitação à Secretaria do PPG em Educação e com autorização do Colegiado do PPG, tivemos acesso aos relatórios produzidos, totalizando 94 exemplares. Diante de um número expressivo de relatórios, optamos em estabelecer o critério temporal, selecionando os relatórios mais recentes, sendo estes os produzidos nos anos de 2015 e 2016. Portanto, o corpus desta pesquisa é composto de 15 relatórios, sendo 5 escritos no ano de 2015 e 10 no ano de 2016.

Os relatórios são caracterizados como documentos e foram analisados por meio da Análise Documental proposta por Cellard (2012) que indica, como primeira etapa, que o documento passe por uma análise preliminar crítica composta por cinco dimensões: o contexto; o autor; a autenticidade e a confiabilidade do texto; a natureza do texto; os conceitos-chave e a lógica interna do texto.

Como segunda etapa, realiza-se a análise textual do documento, considerando os elementos analisados na etapa anterior. Em consonância com o objetivo desta pesquisa, identificamos que na seção “Conclusão” dos relatórios há mais marcas das impressões do autor, assim, elegemos apenas essa seção para análise. Considerando a ética na pesquisa, optamos em preservar a identidade dos autores desses relatórios de ED, substituindo os nomes por letras, nomeados, ao longo do texto, como A, B, C, e assim sucessivamente. Também ocultamos o nome da Universidade na qual a pesquisa foi realizada.

\section{ANÁLISE PRELIMINAR DOS RELATÓRIOS DE ESTAGÍO DE DOCÊNCIA}

Primeiramente, seguindo a proposta de Análise Documental, apresentamos a análise preliminar dos documentos, na qual identificamos cada dimensão proposta por Cellard (2012): o contexto; o autor; a autenticidade e a confiabilidade; a natureza do texto; os conceitos-chave e a lógica interna do texto.

Os relatórios foram produzidos em contexto acadêmico, durante a realização do Curso de Mestrado em Educação, período no qual o mestrando está imerso em atividades acadêmicas de escrita e produção intelectual. Conforme a Resolução nº 047 (UNIVERSIDADE, 2012), o mestrando deve realizar o ED em disciplina de Graduação ou Pós-Graduação da Universidade e sob a supervisão do docente da disciplina. Salientamos que o ED e, por consequência, o relatório são obrigatórios para os mestrandos bolsistas, ficando a critério o período de sua realização. 
Dos cinco relatórios produzidos em 2015, um relatório possui dois autores, pois o estágio foi realizado em dupla e os mestrandos optaram por escrever um relatório. Dos estagiários, quatro eram bolsistas e dois não; os seis estagiários possuem formação inicial em cursos de licenciatura; dois estagiários realizaram o ED com o orientador do mestrado e quatro realizaram com outro docente da universidade.

Dos dez relatórios produzidos em 2016, oito estagiários eram bolsistas e dois, não. Desses, sete estagiários possuem formação inicial em cursos de licenciatura e três possuem formação inicial em cursos de bacharelado. Cinco estagiários realizaram o ED com o orientador do mestrado e cinco realizaram com outro docente.

Os autores dos relatórios são mestrandos, pois é exigência da Universidade investigada que, para realizar o ED, o estagiário esteja matriculado em um dos PPG stricto sensu da Universidade, conforme exposto no artigo $2^{\circ}$ da Resolução $n^{\circ} 047$ (UNIVERSIDADE, 2012). Os 15 relatórios foram produzidos por mestrandos regularmente matriculados no Curso de Mestrado do PPG em Educação no período de 2015 e 2016. Dos 16 mestrandos que realizaram o ED, 12 - (a maioria) - eram bolsistas e 13 tinham contato prévio com a docência por terem formação em licenciatura enquanto três tiveram seu primeiro contato durante o ED.

Identificamos que, investigando as dimensões autenticidade e a confiabilidade do texto, os relatórios são entregues à secretaria do Curso de Mestrado após o término do ED pelo próprio mestrando, a fim de comprovar a sua realização. Compõem o relatório um anexo padronizado pela Resolução nº 047 (UNIVERSIDADE, 2012), identificado como ficha de avaliação padronizada. A ficha, além de conter informações sobre a realização do estágio, conta com espaços para assinaturas do docente orientador de estágio, do orientador de mestrado e do coordenador do Curso de Graduação em que o estágio foi realizado. Há ainda um espaço de avaliação final do estágio que deve ser preenchido pelo docente orientador de estágio e um campo a ser assinalado, indicando a aprovação ou não do mestrando.

Cellard (2012, p. 302) afirma que "não é possível exprimir-se com a mesma liberdade em um relatório destinado aos seus superiores, e em seu diário íntimo”. Entendemos que o relatório de ED tem como objetivos descrever as experiências do estagiário, comprovar a realização do ED e obter aprovação no ED. Dessa forma, voltando a Cellard (2012), o relato dessas experiências, além de não acontecer com liberdade, dá-se com a finalidade de aprovação final.

Quanto à natureza do texto, é um relatório com características descritivas da atuação no campo de estágio, desenvolvido a fim de registrar as experiências do estagiário e obter aprovação no ED. Sobre os conceitos-chave e a lógica interna do texto, os 15 relatórios possuem o mesmo formato, sendo este padronizado e disponibilizado pelo Mestrado em Educação, um modelo composto de 8 seções: introdução; descrição da turma; período de realização; preparação das aulas; conteúdos abordados; metodologia de ensino; avaliação e conclusão. Além disso, há o anexo: ficha de avaliação. Em média, os relatórios possuem 9 páginas

Realizada a análise preliminar dos documentos, apresentamos, na próxima seção, a segunda etapa que visa reunir as dimensões apresentadas com o texto dos documentos, buscando alcançar o objetivo desta pesquisa. 


\section{PERCEPÇÕES ATRIBUÍDAS AO ESTÁGIO DOCENTE}

Para alcançar o objetivo desta pesquisa, analisamos especificamente a seção "Conclusão" dos relatórios de ED produzidos pelos mestrandos. Nessa seção, identificamos as percepções atribuídas pelos mestrandos ao ED que mais se destacaram, sendo estas: aprendizado da prática docente no ES; valorização do docente orientador de estágio; papel da docência e lições adquiridas no estágio de docência.

\subsection{APRENDIZADO DA PRÁTICA DOCENTE NO ENSINO SUPERIOR}

Identificamos que os mestrandos, em sua maioria, auxiliaram na elaboração de planos de ensino e avaliações, bem como em demais atividades previstas no artigo $6^{\circ}$ da Resolução $n^{\circ} 047$ (UNIVERSIDADE, 2012), que orienta o estudante a auxiliar o docente orientador de estágio nas atividades de docência:

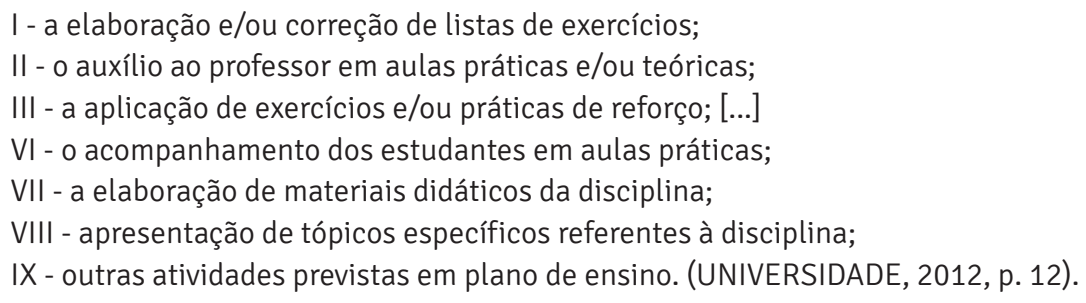

Essas atividades são inerentes à docência e foram relatadas pelos mestrandos que destacaram a importância da elaboração de procedimentos didáticos e do exercício do ED no seu percurso formativo, conforme um dos relatos: "Realizar um estágio de docência no ensino superior foi de extrema relevância para minha formação acadêmica e profissional, pois me permitiu que vivenciasse e experimentasse a rotina de preparação de aulas e regência no ensino superior" (MESTRANDO A, 2016).

Joaquim, Vilas Boas e Carrieri (2013), em uma pesquisa realizada com estagiários docentes da Pós-Graduação, identificaram que "os alunos veem no estágio docente uma oportunidade de aprender técnicas que, até então, não faziam parte de seus conhecimentos tácitos” (JOAQUIM; VILAS BOAS; CARRIERI, 2013, p. 360). Os pesquisadores apontaram ainda que uma das motivações identificadas para realizar o ED foi a possibilidade de desenvolver essas habilidades técnicas e os procedimentos didáticos.

Esse sentido é descrito no registro do Mestrando B “[...] percebo que o planejamento e organização das aulas com base no cronograma facilita o trabalho do professor com relação à organização das atividades" (MESTRANDO B, 2016). Anastasiou e Alves (2004) apontam que a seleção de conteúdos e de conceitos é um dos grandes desafios do docente do ES, aos quais ainda se deve atribuir a estratégia de ensino. Vivenciar esse processo de planejamento da aula durante o ED contribui para a formação do mestrando como futuro docente do ES.

Outro ponto destacado nos relatórios pelos mestrandos é a possibilidade de vivência da docência no ES, conforme escreveu o mestrando A (2016): "O desafio de conduzir algumas aulas proporcionou um maior contato com a realidade da sala de aula do ensino superior e foi uma ótima oportunidade 
para experimentar a docência”. Sobre isso, Soares e Cunha (2010) reforçam que a articulação entre teoria e prática são elementos essenciais do currículo voltado para a formação do docente no ES, no qual ele deve ir além de saber o conhecimento específico, precisando dominar a pedagogia.

Diante disso, a importância em realizar atividades práticas durante o ED possibilita o exercício de planejamento didático que engloba o domínio do conhecimento científico e adentra no conhecimento pedagógico, como exposto a seguir:

Outro ponto a ser destacado, foi o processo de avaliação das produções dos estudantes, pensar nas atividades, acompanhar o processo de construção pelos estudantes, elaborar critérios de avaliação e fazer uma devolutiva de cada atividade e do projeto de pesquisa foram exercícios marcantes, e que servirão de base para reflexões e práticas docentes futuras. (MESTRANDO A, 2016).

Nesse relato, evidencia-se a relevância do processo prático, o mestrando salienta que o conhecimento adquirido e a experiência prática realizados no ED contribuirão em seu futuro como docente do ES. Isso é percebido também por mestrandos que já possuíam experiência docente com a Educação Básica, como afirma o mestrando C (2016): “o estágio de docência se faz muito importante pois possibilita o contato com o planejamento, a docência e a vivência no Ensino Superior, muito diferente da formação e da atuação na educação básica”. Apesar de citar que há diferenças na atuação no ES e na Educação Básica, o mestrando C não especifica essas diferenças, o que seria uma questão de relevância para entendermos a importância de realizar o ED na Pós-Graduação.

Diante disso, é evidente a necessidade da formação específica para atuar como docente no ES, inclusive para aqueles com experiência docente na Educação Básica, visto que há diferenças entre os diferentes níveis de ensino.

\subsection{VALORIZAÇ̃̃O DO DOCENTE ORIENTADOR DE ESTÁGIO}

Os mestrandos sinalizaram, nos relatórios de estágio, a importância de aprender na prática e sob a orientação de um docente. 0 mestrando $D$ relata sobre o docente orientador: "[...] me proporcionou a aproximação e aprendizagens com um professor experiente na área” (MESTRANDO D, 2016). Pachane (2006) destaca que, quando a formação docente ocorre com atividade prática, como acontece no ED, o estagiário conta com o acompanhamento de um docente que irá exercer a figura de mentor, tutor ou orientador, este "apresenta-se como um ponto de maior segurança para que o aluno desenvolva o seu trabalho e também como 'provocador' dos processos de reflexão do estudante” (PACHANE, 2006, p.126, grifo do autor).

O mestrando E (2015) também relata o acompanhamento do docente: “[...] nos proporcionou conviver e aprender com alguém experiente na área e com os acadêmicos que, como nós, estão em processo de construção de suas identidades". Por meio desses relatos, podemos perceber a importância de aprender na prática, com o acompanhamento de um docente que oriente esse processo de formação, exercendo o papel de mentor ou orientador. No relato do mestrando E ainda é possível identificar 
que ele reflete sobre o processo de aprendizagem dos acadêmicos da disciplina em que realizou o ED, no qual ele se percebe como aprendiz e como docente, afirmando ter aprendido tanto com o docente, quanto com os acadêmicos que estão construindo as suas identidades.

\subsection{PAPEL DA DOCÊNCIA}

O ED também permitiu aos mestrandos a reflexão sobre o papel do docente no ES não mais como detentor do conhecimento, mas sim como um mediador, conforme relato da mestranda F: "Tive de aprofundar termos para poder debater, rever conceitos, buscar novas ideias e novos teóricos que me auxiliassem no processo de troca de ideias, sendo eu a mediadora da história" (MESTRANDO F, 2016). Observamos, nesse relato, que ensinar exige, além do conhecimento específico, o domínio de conhecimentos pedagógicos, como mencionado na introdução desta pesquisa.

Para além disso, no relato do estagiário G (2015), notamos uma reflexão sobre a sua identidade docente: "[...] pude rever os meus conceitos acerca do que é ser professor: muito mais do que conhecer uma série de conteúdos e metodologias, tem a ver com dedicação, compreensão e habilidades não somente profissionais, mas também humanas". Segundo Isaia (2006, p. 78), "a reflexão sobre a própria prática pode ser entendida como condição de formação e de desenvolvimento profissional. Contudo, é preciso enfatizar que a prática por si só não gera conhecimento". Dessa forma, compreendemos que o ED vai além da atividade prática docente quando o mestrando consegue realizar esse processo de reflexão sobre a prática, que pode acontecer, sobretudo durante o processo de escrita do Relatório de ED.

No relato do mestrando G (2015), destaca-se que o docente, além das habilidades profissionais, necessita desenvolver as habilidades humanas. Conforme Cunha (2000), não cabe mais ao docente uma função de transmissão de conhecimento, pois, atualmente, esse acesso pode se dar por outros meios, como a comunicação e a tecnologia. Existe, porém, algo que não conseguimos por meio da tecnologia: a sensibilidade humana. Tal sensibilidade pode interferir no conhecimento como uma ponte entre este e as estruturas cognitivas, culturais e afetivas dos educandos.

\subsection{LIÇÕES ADQUIRIDAS NO ESTÁGIO DE DOCÊNCIA}

Entre as múltiplas dimensões que envolvem a pedagogia universitária está a capacidade de escuta atenta, acima da capacidade do discurso (CUNHA, 2012). Assim, cria-se uma expectativa de reciprocidade entre o docente e o estudante, fazendo com que sejam reconhecidos os saberes do outro. Isto é percebido na reflexão do mestrando $H$ (2016), que afirma ser esta uma das lições adquiridas no ED: "A primeira lição, é que no decorrer das aulas saber escutar as aflições e os problemas dos estudantes é fundamental para começar um diálogo frutífero". Para Pachane (2006, p.134), o processo “formação pedagógica não se limita aos aspectos práticos (didáticos ou metodológicos) do fazer docente, porém engloba dimensões relativas a questões éticas, afetivas e político-sociais envolvidas na docência”, o que é citado pelo mestrando $\mathrm{H}$ como primeira lição: saber escutar.

O mestrando H (2016) aponta ainda que a "Outra lição deixada pela experiência foi o contato com os estudantes de um ângulo diferente." Esse dado foi encontrado na pesquisa de Joaquim, Vilas Boas 
e Carrieri (2013, p. 360), quando afirmam que os estudantes, durante o estágio, "têm a possibilidade de conhecer uma realidade por um ângulo diferente daquele já experimentado outrora". 0 ângulo vivenciado anteriormente é o de estudante e que, no momento do estágio, passa a ser de docente, o mestrando passa a oscilar entre estudante da pós-graduação e docente durante o ED. Por fim, o mestrando H (2016) afirma que o ED “[...] proporcionou uma maior confiança em si e o desejo de continuar a trilhar o caminho de pesquisador e professor docente".

Por meio dos relatos dos mestrandos, podemos perceber impressões positivas sobre a experiência de docência no ES vivenciada durante o ED. Para a maioria dos mestrandos, esse foi o primeiro contato com a docência no ES, como descrevem as mestrandas I e J (2015): "Esta foi a primeira experiência com o ensino superior e resultou em aprendizagens ricas, significativas e profundas". Nesse relato, as mestrandas I e J apresentam apenas aspectos positivos da experiência de docência no ES, não especificando quais são, o mesmo acontece no relato do Mestrando H (2016): “avalio este estágio na docência como positivo".

Já em outra parte do relato das mestrandas I e J (2015), consta que "o estágio docência proporcionou-nos vivenciar, enquanto docentes, o cotidiano do Ensino Superior, seus imprevistos suas dificuldades, seus desafios e seus encantos". As mestrandas apontam lacunas e dificuldades no ED, mas não especificam-nas o que nos falta para analisar mais apuradamente a situação. Podemos questionar se essa falta de especificação dos aspectos tanto positivos quanto negativos na docência no ES se deu por um constrangimento em relatá-los, visto os enfoques verificados na análise crítica preliminar nas dimensões: autenticidade, confiabilidade do texto, e natureza do texto, no qual o relatório de estágio é avaliado e aprovado pelo docente orientador do ED.

\section{CONSIDERAÇÕES}

A partir da análise realizada, entendemos que o ED proporciona aos mestrandos uma experiência com a docência no ES, a partir do desenvolvimento de atividades inerentes à profissão sob a orientação de um docente da Universidade. Além disso, o mestrando tem a oportunidade de colocar em prática o aprendizado teórico, contribuindo para a sua formação docente. Conforme Cunha (2012), a qualidade do ES depende de docentes qualificados que dominem tanto o conhecimento científico, quanto o conhecimento pedagógico.

Salientamos ainda que são os PPG stricto sensu responsáveis pela formação do docente do ES e que há obrigatoriedade de os bolsistas CAPES realizarem o ED, devendo ser um processo de formação docente adequado às necessidades do ES.

Ao verificar apenas os documentos, sem considerar as dimensões da análise preliminar, poderíamos concluir que o ED foi excelente, visto que, nos 15 relatórios, não foram identificadas críticas ao ED, apresentadas pelos mestrandos no período do estágio. Foram sinalizadas dificuldades no ED, mas não foram especificadas quais são. Diante disso, voltamos a Cellard (2012) e ao procedimento para a Análise Documental e, retomando a análise preliminar do documento, identificamos que os relatórios 
são entregues à secretaria do Curso de Mestrado em Educação e avaliados pelo docente orientador que indica a aprovação ou não do mestrando no ED.

Diante desse fluxo, o mestrando pode não relatar, por exemplo, possíveis conflitos com o docente orientador ou críticas sobre o desenvolvimento do ED, o que pode comprometer a confiabilidade do texto, ou seja, o fato de o relatório ser avaliado pelo docente orientador pode influenciar diretamente na descrição do desenvolvimento do estágio.

A avaliação do ED no PPG investigado, dá-se sobre os relatórios de ED, mas, se os relatórios não especificam as informações, não apresentam críticas e sugestões, também não indicam possíveis mudanças em relação ao ED. Dessa forma, uma das seções do relatório poderia apontar sugestões de melhorias no processo do ED, ou a avaliação do mestrando no ED não deveria estar atrelada ao relatório. Assim, parecem-nos necessárias investigações posteriores a esta, com intuito de identificar como ocorrem os processos formativos no ED e elucidar proposições para qualificar o ED e a formação docente para o ES no PPG investigado.

\section{REFERÊNCIAS}

ANASTASIOU, Léa das Graças Camargos; ALVES, Leonir Pessate (Orgs.). Processos de ensinagem na universidade: pressupostos para as estratégias de trabalho em aula. 3. ed. Joinville: Univille, 2004.

BRASIL. Lei nº 9.394/96, de 20 de dezembro de 1996. Estabelece as diretrizes e bases da educação nacional. Brasília, Disponível em: goo.gl/js2ZW4. Acesso em: 12 maio 2017.

CAPES. Portaria $\mathbf{n}^{\mathbf{0}} \mathbf{7 6}$, de 14 de abril de 2010. Regulamenta o programa de Demanda Social - DS. Disponível em: goo.gl/CQatBR. Acesso em: 11 ago. 2017.

CELLARD, A. Análise documental. In: POUPART, J. et al. (Org.). A pesquisa qualitativa: enfoques epistemológicos e metodológicos. 3. ed. Petrópolis: Editora Vozes, 2012. p. 295-316.

CUNHA, M. I. Ensino como mediação da formação do professor universitário. In: MOROSINI, M. C. (Org.). Professor do ensino superior: identidade, docência e formação. Brasília: Instituto Nacional de Estudos e Pesquisas Educacionais, 2000. Cap. 3. p. 45-52.

CUNHA, M. I. Docência no ensino superior: perguntas necessárias ao campo da pós-graduação. In: LEITE, Y. U. F. et al. (Org.). Políticas de formação inicial e continuada de professores. Araraquara: Junqueira\&Marin Editores, 2012. p. 298-306.

ISAIA, S. M. A. Desafios à docência superior: pressupostos a considerar. In: RISTOFF, D.; SEVEGNANI, P. (Org.). Docência na educação superior. Brasília: Instituto Nacional de Estudos e Pesquisas Educacionais Anísio Teixeira, 2006. Cap. 1. p. 63-84. 
JOAQUIM, N. de F.; VILAS BOAS, A. A.; CARRIERI, A. de P. Estágio docente: formação profissional, preparação para o ensino ou docência em caráter precário? Educação e Pesquisa, São Paulo, v. 39, n. 2, p. 351-365, abr./jun. 2013.

LIMA, M. S. L.; BRAGA, M. M. S. C. Relação ensino-aprendizagem da docência: traços da pedagogia de Paulo Freire no ensino superior. Educar em Revista, Curitiba, v. 32, n. 61, p.71-88, jul./set. 2016.

PACHANE, G. G. Teoria e prática na formação de professores universitário: elementos para discussão. In: RISTOFF, D.; SEVEGNANI, P. (Org.). Docência na educação superior. Brasília: Instituto Nacional de Estudos e Pesquisas Educacionais Anísio Teixeira, 2006. Cap. 1. p. 97-145.

SOARES, S. R.; CUNHA, M. I. Formação do professor: a docência universitária em busca de legitimidade. Salvador: EDUFBA, 2010.

UNIVERSIDADE. Resolução Interna n⿳0 047, de 08 de novembro de 2012. Aprova o Regulamento do Estágio Docência na Instituição. Cidade, 2012.

VEIGA, I. P. Docência universitária na educação superior. In: RISTOFF, D.; SEVEGNANI, P. (Org.). Docência na educação superior. Brasília: Instituto Nacional de Estudos e Pesquisas Educacionais Anísio Teixeira, 2006. Cap. 1. p. 85-96.

ZANCHET, B. A.; CUNHA, M. I.; SOUSA, H. M. A pós-graduação em educação como lugar de formação e aprendizagens de professores universitários. Educação, Sociedade \& Culturas, n. 28, p. 93-105. 2009. 
Recebido em: 9 de Fevereiro de 2018

Avaliado em: 20 de Abril de 2018

Aceito em: 20 de Abril de 2018

1 Mestre em Educação pela Universidade Regional de Blumenau - FURB; Graduada em Nutrição (2013) - FAMEBLU; Bolsista FAPESC. E-mail: nutricionista@juliagraciela.com.br

2 Especialista em Educação Musical pela Associação Catarinense de Ensino da Faculdade Guilherme Guimbala (2012); Mestranda em Educação pela Universidade Regional de Blumenau - FURB; Graduada em Artes com Licenciatura em Música (2006) - FURB. Bolsista CAPES. E mail: marianalopesjunqueira@gmail.com

3 Doutora em Educação; Pesquisadora e professora do Programa de Pós-Graduação em Educação da Universidade Regional de Blumenau; Líder do Grupo de Estudos e Pesquisas em Educação Superior - GEPES

E-mail: selpamarcia@gmail.com

\section{Como citar este artigo:}

ROMEO, Andrea. Lo special account del fenomeno religioso nel dibattito nordamericano. Argumenta Journal Law, Jacarezinho - PR, Brasil, n. 29., 2018, p. 15-48. DOI: 10.17564/2316-3828.2018v7n1p13-24

\section{(2) (1) ()}

Este artigo é licenciado na modalidade acesso abertosob a Atribuição-Compartilhalgual CC BY-SA

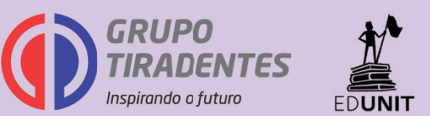


